\title{
Mediating Effects of Relationship Quality on Franchisor Leadership and Franchisee Performance
}

\author{
Joon-Ho Kim ${ }^{1}$, Chun-Sung Youn ${ }^{2 *}$ \\ ${ }^{1}$ College of General Education, Semyung University, Jecheon-si, Chungcheongbuk-do, Korea \\ ${ }^{2}$ Department of Convergence Industry, Seoul Venture University, Seoul, Korea
}

\author{
"Corresponding author: Chun-Sung Youn, \\ Department of Convergence Industry, Seoul \\ Venture University, 405 Bongeunsa-ro, \\ Samsung-dong, Gangnam-gu, Seoul 06097 , \\ Korea \\ Tel.: +82 234705268 \\ Fax: +82234705267 \\ Email: staryoun@svu.ac.kr
}

Received June 12, 2017

Revised September 12, 2017

Accepted October 13, 2017

Published December 30, 2017

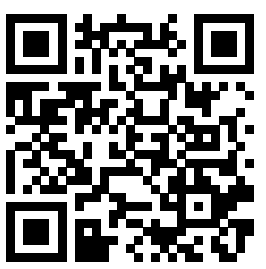

\begin{abstract}
Purpose: The purpose of this study is to examine the mediating effects of relationship quality on franchisor instructor's leadership and franchisee business performance. Methods: Frequency analysis was used to analyze general characteristics of the data surveyed. Factor analysis and Cronbach's $\alpha$ were conducted to verify the validity and reliability of the variables. In addition, multiple linear regression analysis was employed to investigate the impact of variables. Results: The results showed that the regression coefficient of the independent variable (i.e., transformational leadership) had smaller effects at the third stage than at the second stage in the three-step mediated regression. In addition, the mediating effects of relationship qualities (i.e., satisfaction and trust) on the relationship between franchisor instructor's leadership and franchisee performance were significantly positive. Therefore, relationship qualities partially mediated the relationship between the franchisor instructor's transformational leadership and franchisee performance (i.e., learning and growth performance and internal process performance). Conclusion: Based on the results of this study, service franchisors should apply transformational leadership more actively when implementing a training program for franchisee's employees and improve their communication tools in order to ensure the franchisee's satisfaction and trust in the franchise system.
\end{abstract}

Keywords: Franchisee, Leadership, Satisfaction, Trust, Performance

\section{Introduction}

생활수준의 향상으로 웰빙(well-being)과 아름다움(美)에 대한 관심과 욕구가 증대하면서 뷰티산업은 지속적으로 성장 하고 있다. 특히 뷰티산업은 관광 - 수출 콘텐츠로서 큰 잠재력 을 보유하고 있으며, 노동집약적인 산업특성으로 고용창출 효 과가 크므로 서비스 분야의 신성장 동력 산업으로 주목 받고 있다(Kim, 2016).

뷰티산업은 화장품 등 제조 산업과 점포 시술 등 서비스 산 업으로 구분되며, 특히 헤어 서비스 산업은 뷰티 서비스 산업 중 가장 규모가 크고 프랜차이즈 업체의 활동이 활발한 분야이 다(Lee \& An, 2014). 뷰티 서비스 산업은 점포에서 직접 고객 을 대면하고 시술이 이루어지므로, 규모를 확대하기 위해 프 랜차이즈 방식의 가맹점 모집에 적극적이다. 뷰티 서비스 산업
선진국이라 할 수 있는 미국에는 Regis Group, Great Clips, Fantastic Sams 등 수천 개 이상의 점포를 보유한 대형 헤어 프랜차이즈들이 있으며, 특히 Regis Group은 뉴욕증권거래소 에 상장되어 있을 만큼 규모의 대형화, 업종의 전문화가 이루 어져 있다.

서비스 프랜차이즈의 성공을 위해 규격화, 통일화된 서비스 제공이 중요하지만 헤어 프랜차이즈는 시술자의 기술과 특성 에 서비스의 질이 크게 의존하는 특징으로 표준화된 서비스를 제공하는 프랜차이즈의 강점을 살려나가는데 애로 사항이 있 다. 따라서 외식업, 유통업 등 프랜차이즈는 본사로부터 규격 화된 제품의 공급이 중요하여 슈퍼바이저, 물류 시스템, 현장 판촉 등 일원화된 마케팅 지원 등이 가맹점 경영성과에 중요한 요인이나, 헤어 프랜차이즈는 소비자가 신뢰하여 점포를 지속 방문하도록 하는 브랜드 파워와 더불어 가맹점 직원의 역량 증 
대를 위한 본사 교육 프로그램이 무엇보다 중요하다.

그러므로 본사 교육의 리더십 행동유형은 가맹점 직원의 역 량강화에 중요한 요인이 되고, 서비스 프랜차이즈 가맹점의 경 영성과는 직원의 역량에 크게 좌우되므로 가맹본사는 교육 프 로그램 실행에서 가장 효율적인 리더십 유형을 발휘할 필요가 있다(Bass, 1990). 또한 프랜차이즈 시스템에서 본사에 대한 신뢰의 수준은 가맹점이 본사 정책에 순응하는데 선행요인이 되며(Davies et al., 2011), 신뢰와 협력 관계가 형성될 때 비로 소 가맹점은 본사가 기회주의적 행동을 하지 않을 것이라는 믿 음을 갖고 본사와 함께 성장을 도모하려는 노력을 지속하게 된 다.

프랜차이즈 산업의 성장에 따라 프랜차이즈 본사의 리더십 형태와 가맹점의 성과(Yang \& Lee, 2010), 프랜차이즈 본사와 가맹점의 관계품질과 성과(Hoang, 2011)에 대한 연구가 활발 히 진행되고 있다. 그러나 기존의 프랜차이즈 관계품질 연구들 은 주로 외식업 분야에 편중됨으로써 프랜차이즈 시스템이라 는 공통점이 있더라도 업종의 특성에 따라 본사의 리더십과 프 랜차이즈 관계품질 요인이 가맹점 성과에 미치는 영향 관계가 상이할 수 있는 뷰티 서비스 프랜차이즈 업종에 적용시키기에 는 한계가 있다.

또한 프랜차이즈 가맹점 성과를 측정하는 연구(Michael \& Combs, 2008; Park, 2009)가 다수 이루어져 왔으나 가맹점 성과의 측정 요소로서 주로 인지된 재무적 성과를 이용하거나 관계품질 요소로서 몰입의 요소를 강조해 왔다. 관계품질 요 소는 프랜차이즈 본사와 가맹점의 관계마케팅 측면으로 접근 되어야 하며 이를 통해 뷰티 프랜차이즈 시스템 안에서 본사와 가맹점의 상호작용에 대한 이해가 필요하다.

특히 헤어 프랜차이즈는 시술자의 특성에 따라 고객이 받 는 서비스의 품질과 수준이 달라지며, 이를 극복하여 프랜차이 즈 시스템 고유의 장점을 발휘하는 것이 중요한 성공 요인이므 로 타업종 프랜차이즈와 구별되는 특질을 이해하고 가맹점 직 원과 가맹본사 간 관계품질 형성의 고유한 성격을 이해할 필 요가 있다. 이와 같이 우수한 시술 능력과 서비스 마인드를 갖 춘 가맹점 직원의 육성은 뷰티 프랜차이즈의 가장 핵심적인 경 쟁력이 될 것이다. 또한 가맹본사 교육강사의 리더십은 리더 와 구성원의 관계에 따라 변혁적 리더십과 거래적 리더십으로 구분할 수 있다. 변혁적 리더십은 리더가 구성원의 잠재적 동 기를 인지하고 구성원으로부터 내재적 동기를 유발하여 신념, 욕구, 가치의 변화를 추구함으로써 개인, 집단 및 조직의 변화 를 유도하는 리더십이다(Den Hartog et al., 1997). 반면 거래 적 리더십은 리더와 구성원 간 교환관계를 통해 구성원의 이해 관계와 동기를 자극하여 변화를 추구하는 리더십이다(Bono \& Judge, 2004). 변혁적 리더십과 거래적 리더십이 직무성과에 미치는 효과는 구성원의 동기부여가 매개효과로서 영향을 미
칠 수 있으므로 변혁적 리더십과 거래적 리더십의 다른 차원을 감안하여 성과를 평가하는 것이 중요하다(Shin \& Cha, 2014). 따라서 뷰티 프랜차이즈 가맹본사 교육강사의 리더십 유형, 즉 변혁적 리더십과 거래적 리더십이 교육 대상자의 직급에 따 라 가맹점 직원 성과에 미치는 영향 및 가맹점 직원과 가맹본 사 간 프랜차이즈 관계품질의 매개효과를 밝혀 뷰티 프랜차이 즈의 효과적인 운영을 위한 시사점을 제안하는데 본 연구의 목 적이 있다.

\section{Methods}

\section{1. 연구대상}

본 연구의 실증분석을 위해 대형 헤어 프랜차이즈 가맹점에 근무하는 종사자를 대상으로 하였다. 2014년 12월부터 2개월 간 총 500 부의 설문지를 배포하여 485 부를 회수하였고, 그 중 응답이 성실하지 못하거나 누락된 설문을 제외한 476 부를 실 증분석에 사용하였다.

\section{2. 연구내용 및 방법}

1) 설문지의 구성

본 연구에서 사용한 측정도구는 설문지로 총 61 문항으로 구 성하였다. 설문에 사용된 척도는 명목척도를 사용한 인구통계 적 요인을 제외하고, Likert 5점 척도(매우 그렇다=5점; 전혀 아니다=1점)를 이용하여 측정하였다. 선행연구를 바탕으로 독 립변수인 교육강사의 리더십은 변혁적 리더십과 거래적 리더 십으로 구분하였다. 변혁적 리더십은 하위 구성요인으로 카리 스마 3 문항, 이상적 영향 3 문항, 지적자극 3 문항, 개인적 배 려 3 문항, 영감적 동기부여 3 문항으로서 모두 15 문항으로 구 성하였다(Avolio et al., 1999). 거래적 리더십은 하위 구성요 인으로 업적에 따른 보상 3 문항, 적극적인 예외에 의한 관리 3 문항, 소극적인 예외에 의한 관리 3 문항으로서 모두 9 문항으로 구성하였다(Kanste et al., 2007). 종속변수인 가맹점 직원의 경영성과는 학습과 성장 성과 및 내부 프로세스 성과로 구분 하여, 학습과 성장 성과 9 문항, 내부 프로세스 성과 9 문항으로 모두 18문항으로 구성하였다(Hwangbo \& Ha, 2008; Kaplan \& Norton, 1996; Oh, 2010). 매개변수인 관계품질은 만족 과 신뢰로 구분하여, 만족 5 문항, 신뢰 5 문항으로 모두 10 문항 으로 구성하였다(Garbarino \& Johnson, 1999; Geyskens \& Steenkamp, 2000; Hwang \& Lee, 2014). 본 연구의 설문지 구성내용은 Table 1 과 같다.

\section{2) 자료분석방법}

실증분석을 위해 수집된 자료의 통계처리는 데이터 코딩 
Table 1. Contents of questionnaire

\begin{tabular}{lll}
\hline Variables & Status & Contents \\
Background variables & Characteristics of those surveyed & Gender, age, position, etc. \\
Independent variables & Leadership & Transformational leadership \\
Dependent variables & & Transactional leadership \\
& Performance & Learning \& growth \\
Mediating variables & & Internal process \\
Total & Relationship quality & Satisfaction \\
\hline
\end{tabular}

\section{Table 2. General characteristics of subjects}

\begin{tabular}{|c|c|c|c|}
\hline Division & Status & Frequency & $\%$ \\
\hline \multirow{2}{*}{ Gender } & Female & 395 & 83.0 \\
\hline & Male & 81 & 17.0 \\
\hline \multirow{4}{*}{ Age (years) } & Under 20 & 7 & 1.5 \\
\hline & $20-29$ & 426 & 89.0 \\
\hline & $30-39$ & 37 & 7.8 \\
\hline & Over 40 & 6 & 1.3 \\
\hline \multirow{2}{*}{ Position } & Assistant & 374 & 78.6 \\
\hline & Designer & 102 & 21.4 \\
\hline \multirow{3}{*}{ Education } & High school & 185 & 38.9 \\
\hline & College graduate & 206 & 43.3 \\
\hline & Over university & 85 & 17.9 \\
\hline \multirow{4}{*}{ Work experience (years) } & Less than 1 & 123 & 25.8 \\
\hline & $1-2$ & 213 & 44.7 \\
\hline & $3-5$ & 122 & 25.6 \\
\hline & Over 5 & 18 & 3.8 \\
\hline Total & & 476 & 100.0 \\
\hline
\end{tabular}

(data coding)과 데이터 크리닝(data cleaning) 과정을 거쳐, Statistical Package for the Social Sciences (SPSS) 18.0통 계 패키지 프로그램(IBM, USA)을 이용하여 분석하였다. 구체 적으로 조사대상자의 일반적 특성을 알아보기 위하여 빈도분 석을 실시하였다. 측정도구의 타당성을 검증하기 위하여 요인 분석을 실시하였고, 신뢰도 검증을 위하여 Cronbach's $\alpha$ 계수 를 산출하였다. 또한 각 변수 간 상관관계를 알아보기 위하여 상관관계분석을 실시하였고, 가설 검증을 위하여 선형회귀분 석 및 3 단계 매개회귀분석을 실시하였다.

\section{Results and Discussion}

\section{1. 조사대상자의 인구통계학적 특성}

조사대상자의 인구통계학적 특성은 Table 2 와 같다. 빈도분 석 실시 결과, 성별은 여성 $83.0 \%$, 남성 $17.0 \%$ 이며, 연령은 20 대가 $89.5 \%$ 로 가장 많은 비중을 나타냈다. 직급은 어시스턴 트 $78.6 \%$, 디자이너 $21.4 \%$ 이며, 학력은 고졸과 전문대졸 이하 가 전체의 $82.2 \%$ 로 대학교 재학 이상에 비해 높은 비중을 나
타냈다. 근무경력은 1년 미만 $25.8 \%, 1-3$ 년 미만 44.7\%, 3-5 년 미만 $25.6 \%$ 로 가맹본사의 주된 교육 대상자가 여성으로 근 무경력 5년 미만, 전문대졸 이하, 어시스턴트 직급임을 나타냈 다.

\section{2. 변수 선정의 타당성 및 신뢰도}

본 연구를 위해 사용된 설문 항목의 타당성을 검증하고, 공통 요인의 변수를 구분하기 위해 요인분석을 실시하였다. 요인추 출법은 주성분분석법(principal components analysis)을 사용 하였고, 1 이상의 고유치(eigen value) 값을 갖는 요인만을 추 출하였다. 요인회전은 요인을 단순화하기 위해 일반적으로 사 용되는 베리멕스(varimax) 회전을 실시하였다. 각 변수의 요인 간 상관관계 정도를 나타내는 요인적재량(factor loading)의 수 용기준은 보통 \pm 0.30 이면 유의하다고 보지만 본 연구에서는 \pm 0.50 이상을 기준으로 선택하였다. 또한 본 연구는 다문항 척도로 측정된 문항이 동질적인 문항들로 구성되었는지 신뢰도 를 검증하기 위해 Cronbach's $\alpha$ 계수를 산출하여 0.60 이상이 면 신뢰도가 있는 것으로 판단하였다. 
Table 3. Analysis of validity and reliability on leadership

\begin{tabular}{|c|c|c|}
\hline \multirow[b]{2}{*}{ Status } & \multicolumn{2}{|c|}{ Leadership } \\
\hline & $\begin{array}{l}\text { Transformational } \\
\text { leadership }\end{array}$ & $\begin{array}{c}\text { Transactional } \\
\text { leadership }\end{array}$ \\
\hline Help students strengthen their advantages & 0.987 & 0.032 \\
\hline Support students to achieve their goals & 0.972 & 0.020 \\
\hline Have passion for teaching and coaching students & 0.969 & 0.026 \\
\hline Express strong confidence & 0.930 & 0.003 \\
\hline Optimistic about the future & 0.914 & 0.022 \\
\hline Act for deriving respect from students & 0.910 & 0.031 \\
\hline Have confidence for accomplishing students' goals & 0.910 & 0.025 \\
\hline Emphasize valuable worth and belief & 0.894 & 0.038 \\
\hline Make proud to be with instructor & 0.892 & 0.018 \\
\hline Follow old ways to handle problems & 0.879 & -0.006 \\
\hline Solve problems using various perspectives & 0.867 & 0.029 \\
\hline Propose strongly a clear vision for the future & 0.858 & -0.007 \\
\hline Suggest new ways to implement duty & 0.856 & 0.058 \\
\hline Emphasize the importance of setting goals & 0.836 & 0.045 \\
\hline Respect students' personality & 0.686 & 0.054 \\
\hline Help students only when they show their efforts & 0.009 & 0.915 \\
\hline Hesitate to correct in advance without clearly being mistaken & 0.039 & 0.893 \\
\hline Set clear rewards for achieving goals & 0.031 & 0.885 \\
\hline Take actions only after something goes wrong & -0.033 & 0.882 \\
\hline Try to prevent mistakes and correct them when they happen & -0.038 & 0.872 \\
\hline Specify who contributes to achieving goals & 0.018 & 0.860 \\
\hline Try not to fail to reach a standard & 0.028 & 0.858 \\
\hline Observe mistakes that may happen & 0.066 & 0.847 \\
\hline Take action only after the problem worsens & 0.111 & 0.800 \\
\hline Eigen value & 11.995 & 6.809 \\
\hline Variance (\%) & 49.981 & 28.372 \\
\hline Cumulative variance (\%) & 49.981 & 78.353 \\
\hline Reliability & 0.981 & 0.960 \\
\hline
\end{tabular}

$\mathrm{KMO}=0.968 ; x^{2}=15054.141(\mathrm{df}=276$, Sig. $=0.000)$.

$\mathrm{KMO}$, Keiser-Meyer-Olkin; $x^{2}$, chi-square; df, degrees of freedom; Sig., significance.

\section{1) 리더십에 대한 타당성 및 신뢰도 검증}

교육강사의 리더십과 관련하여 요인분석을 실시한 결과는 Table 3 과 같다. Bartlett의 단위행렬 점검 결과 $\chi^{2}=15054.141$ 로 변수들 사이에 요인을 이룰만한 상관관계가 충분하고, Keiser-Meyer-Olkin (KMO) 표본적합도 점검 결과 0.968 로 나타나 요인분석을 실시하였다. 요인분석 결과 2 개의 요인 이 도출되었고 요인 1 은 리더가 조직구성원에게 집단의 목적 을 인지하도록 하고 집단의 이익을 위해 자신의 이익을 희생할 수 있도록 동기를 부여하는 변혁적 리더십(transformational leadership), 요인 2는 리더가 상황에 따른 보상에 기초하여 부 하에게 영향력을 행사하는 과정으로, 리더와 하급자 간의 교환 관계에 초점을 둔 거래적 리더십(transactional leadership)으
로 명명하였다. 요인의 누적분산설명력은 $78.353 \%$, 신뢰도계 수는 0.8 이상으로 신뢰할 만한 수준으로 나타났다.

\section{2) 관계품질에 대한 타당성 및 신뢰도 검증}

관계품질과 관련하여 요인분석을 실시한 결과는 Table 4 와 같다. Bartlett의 단위행렬 점검 결과 $\chi^{2}=2837.088$ 로 변수들 사이에 요인을 이룰만한 상관관계가 충분하고, $\mathrm{KMO}$ 표본적합 도 점검 결과 0.915 로 나타나 요인분석을 실시하였다. 요인분 석 결과 2 개의 요인이 도출되었고 요인 1 은 가맹점 직원이 가 맹본사와의 업무관계에 대한 평가로부터 긍정적인 정서 상태 를 나타내는 만족(satisfaction), 요인 2 는 가맹점 직원이 가맹 본사의 약속을 믿고, 가맹본사가 교환관계에서 의무를 다할 것 
Table 4. Analysis of validity and reliability on relationship quality

\begin{tabular}{|c|c|c|}
\hline \multirow{2}{*}{ Status } & \multicolumn{2}{|c|}{ Relationship quality } \\
\hline & Satisfaction & Trust \\
\hline Support high-quality marketing and promotion campaigns & 0.866 & 0.378 \\
\hline Provide an efficient price discount policy, such as membership card & 0.813 & 0.286 \\
\hline Provide high-quality product and service & 0.793 & 0.269 \\
\hline Suggest effective guide for successful operation & 0.782 & 0.237 \\
\hline Respect the franchisee's opinion & 0.773 & 0.225 \\
\hline Have reliable information provided by franchisor & 0.209 & 0.737 \\
\hline Provide better quality training programs than the competitors & 0.520 & 0.718 \\
\hline Be interested in the franchisee's success & 0.346 & 0.713 \\
\hline Provide reliable products to franchisee & 0.257 & 0.665 \\
\hline Try to keep promise & 0.127 & 0.648 \\
\hline Eigen value & 3.765 & 2.832 \\
\hline Variance (\%) & 37.648 & 28.320 \\
\hline Cumulative variance (\%) & 37.648 & 65.968 \\
\hline Reliability & 0.906 & 0.809 \\
\hline
\end{tabular}

$\mathrm{KMO}=0.915 ; \mathrm{x}^{2}=2837.088(\mathrm{df}=45$, Sig. $=0.000)$.

$\mathrm{KMO}$, Keiser-Meyer-Olkin; $x^{2}$, chi-square; df, degrees of freedom; Sig., significance.

Table 5. Analysis of validity and reliability on performance

\begin{tabular}{|c|c|c|}
\hline \multirow{2}{*}{ Status } & \multicolumn{2}{|c|}{ Performance } \\
\hline & Learning \& growth & Internal process \\
\hline Try to motivate each other & 0.777 & 0.275 \\
\hline Offer appropriate time for training & 0.756 & 0.284 \\
\hline Keep communication channels to resolve members' complaints & 0.746 & 0.332 \\
\hline Hold technical skills of members high & 0.729 & 0.291 \\
\hline Share knowledge and information & 0.696 & 0.325 \\
\hline Hire talented employee easily & 0.688 & 0.337 \\
\hline Have a low turnover rate & 0.687 & 0.286 \\
\hline Have appropriate empowerment according to position & 0.675 & 0.291 \\
\hline Show high satisfaction from members & 0.588 & 0.287 \\
\hline Give relevant information of new products and trends to customers & 0.310 & 0.718 \\
\hline Accept members' suggestions appropriately & 0.343 & 0.705 \\
\hline Attract new customers by customer segmentation & 0.216 & 0.690 \\
\hline Provide an easy-to-use reservation service and notification of revisiting time & 0.356 & 0.684 \\
\hline Have close cooperation among members & 0.249 & 0.673 \\
\hline Provide quick customer service by shortening waiting time & 0.205 & 0.661 \\
\hline Organize cost management by using relevant quantities of products & 0.340 & 0.640 \\
\hline Provide a higher quality service to customers than the competitors & 0.312 & 0.625 \\
\hline Handle customer complaints promptly and smoothly & 0.334 & 0.568 \\
\hline Eigen value & 5.310 & 4.787 \\
\hline Variance (\%) & 29.498 & 26.593 \\
\hline Cumulative variance (\%) & 29.498 & 56.091 \\
\hline Reliability & 0.913 & 0.887 \\
\hline
\end{tabular}

$\mathrm{KMO}=0.954 ; \mathrm{x}^{2}=4457.989$ (df=153, Sig. $\left.=0.000\right)$.

$\mathrm{KMO}$, Keiser-Meyer-Olkin; $x^{2}$, chi-square; df, degrees of freedom; Sig., significance. 
Table 6. Correlation among variables

\begin{tabular}{|c|c|c|c|c|c|c|c|}
\hline \multirow[b]{2}{*}{ Status } & & \multicolumn{2}{|c|}{ Leadership } & \multicolumn{2}{|c|}{ Relationship quality } & \multicolumn{2}{|c|}{ performance } \\
\hline & & $\begin{array}{l}\text { Transformational } \\
\text { leadership }\end{array}$ & $\begin{array}{c}\text { Transactional } \\
\text { leadership }\end{array}$ & Satisfaction & Trust & $\begin{array}{l}\text { Learning \& } \\
\text { growth }\end{array}$ & Internal process \\
\hline \multirow{2}{*}{ Leadership } & $\begin{array}{l}\text { Transformational } \\
\text { leadership }\end{array}$ & 1 & & & & & \\
\hline & $\begin{array}{l}\text { Transactional } \\
\text { leadership }\end{array}$ & 0.058 & 1 & & & & \\
\hline \multirow{2}{*}{$\begin{array}{l}\text { Relationship } \\
\text { quality }\end{array}$} & Satisfaction & $0.424^{* * *}$ & $0.108^{*}$ & 1 & & & \\
\hline & Trust & $0.451^{* * *}$ & 0.068 & $0.661^{* * *}$ & 1 & & \\
\hline \multirow{2}{*}{ Performance } & Learning \& growth & $0.452^{* * *}$ & 0.048 & $0.606^{* * *}$ & $0.661^{* * *}$ & 1 & \\
\hline & Internal process & $0.422^{* * *}$ & 0.054 & $0.559^{* * *}$ & $0.606^{* * *}$ & $0.578^{* * *}$ & 1 \\
\hline
\end{tabular}

${ }^{*} p<0.05 ;{ }^{* * *} p<0.001$.

Table 7. Mediating effects of satisfaction on the relationship between transformational leadership and performance

\begin{tabular}{|c|c|c|c|c|c|c|c|}
\hline \multirow{2}{*}{ Step } & & \multicolumn{3}{|c|}{ Learning \& growth } & \multicolumn{3}{|c|}{ Internal process } \\
\hline & & $\beta$ & $t$ & $p$ & $\beta$ & $t$ & $p$ \\
\hline Step 1 & & 0.424 & $10.187^{* \star *}$ & 0.000 & 0.424 & $10.187^{\star \star \star}$ & 0.000 \\
\hline Step 2 & & 0.452 & $11.043^{* * *}$ & 0.000 & 0.422 & $10.147^{* * *}$ & 0.000 \\
\hline \multirow{2}{*}{ Step 3} & $\begin{array}{l}\text { Transformational } \\
\text { leadership }\end{array}$ & 0.238 & $6.133^{* * *}$ & 0.000 & 0.226 & $5.547^{* * *}$ & 0.000 \\
\hline & Satisfaction & 0.505 & $12.991^{* * *}$ & 0.000 & 0.463 & $11.343^{* * *}$ & 0.000 \\
\hline$F$-value & & & $166.944^{* * *}$ & & & $129.685^{* * *}$ & \\
\hline Adjusted $\mathrm{R}^{2}$ & & & 0.411 & & & 0.351 & \\
\hline
\end{tabular}

$\beta$, standardized regression coefficient; $t, t$-value; $p, p$-value; Adjusted $\mathrm{R}^{2}$, adjusted coefficient of determination; ${ }^{* * *} p<0.001$.

으로 믿는 정도를 나타내는 신뢰(trust)로 명명하였다. 요인분 석 결과 2 개의 요인이 도출되었고 요인의 누적분산설명력은 $65.968 \%$, 신뢰도계수는 0.8 이상으로 신뢰할 만한 수준으로 나타났다.

\section{3) 경영성과에 대한 타당성 및 신뢰도 검증}

경영성과와 관련하여 요인분석을 실시한 결과는 Table 5 와 같다. Bartlett의 단위행렬 점검 결과 $\chi^{2}=4457.989$ 로 변수들 사이에 요인을 이룰만한 상관관계가 충분하고, $\mathrm{KMO}$ 표본적합 도 점검 결과 0.954 로 나타나 요인분석을 실시하였다. 요인분 석 결과 2 개의 요인이 도출되었고 요인 1 은 장기적 목표를 달 성하기 위해 조직의 현재 역량과 필요한 역량 사이의 격차를 인 식하고 그 차이를 줄이도록 직원의 재교육, 정보기술과 시스템 을 강화하는 학습과 성장 성과(learning \& growth), 요인 2는 고객에게 가치를 지속적으로 제공하기 위해 프로세스 관점에서 효율성을 제고하여 경쟁우위를 확보하는 내부 프로세스 성과 (internal process)로 명명하였다. 요인분석 결과 2 개의 요인이 도출되었고 요인의 누적분산설명력은 $56.091 \%$, 신뢰도계수는 0.8 이상으로 신뢰할 만한 수준으로 나타났다.

\section{3. 각 변수 간의 상관관계 분석}

각 변수 간의 상관관계 분석을 실시한 결과는 Table 6 과 같 다. 분석결과 교육강사의 변혁적 리더십은 관계품질의 하위요 인인 만족, 신뢰와 통계적으로 유의미한 정 $(+)$ 의 상관관계가 있는 것으로 나타났고 $(p<0.001)$, 경영성과의 하위요인인 학습 과 성장 성과, 내부 프로세스 성과와도 통계적으로 유의미한 정 $(+)$ 의 상관관계가 있는 것으로 나타났다 $(p<0.001)$. 뷰티 프랜 차이즈 업계가 체계화됨에 따라 가맹점 직원이 가맹본사에게 기대하는 수준이 높아지고 해당 프랜차이즈 브랜드에서 장기적 인 비전을 보는 경향이 증가하고 있으므로 가맹본사 교육강사 의 변혁적 리더십이 가맹점 직원들의 미래 성장욕구와 비전 수 립에 영향을 미치며, 따라서 목표 달성을 위한 학습 동기 고취 와 프로세스 개선에 적극적인 태도를 유발하는 것으로 보인다.

또한 관계품질의 하위요인인 만족, 신뢰는 경영성과의 하 위요인인 학습과 성장 성과, 내부 프로세스 성과와 통계적 으로 유의미한 정 $(+)$ 의 상관관계가 있는 것으로 나타났으며 $(p<0.001)$, 학습과 성장 성과와 내부 프로세스 성과 간에도 통 계적으로 유의미한 정(+)의 상관관계가 있는 것으로 나타났다 $(p<0.001)$. 뷰티 프랜차이즈는 가맹본사의 영업 - 마케팅, 경영 관리, research and development (R\&D) 등 전통적인 가맹점 지원정책뿐 아니라 가맹점 직원이 프랜차이즈 시스템에 만족과 
Table 8. Mediating effects of satisfaction on the relationship between transactional leadership and performance

\begin{tabular}{|c|c|c|c|c|c|c|c|}
\hline \multirow{2}{*}{ Step } & & \multicolumn{3}{|c|}{ Learning \& growth } & \multicolumn{3}{|c|}{ Internal process } \\
\hline & & $\beta$ & $t$ & $p$ & $\beta$ & $t$ & $p$ \\
\hline Step 1 & & 0.108 & $2.355^{*}$ & 0.019 & 0.108 & $2.355^{*}$ & 0.019 \\
\hline Step 2 & & 0.048 & 1.052 & 0.293 & 0.054 & 1.178 & 0.239 \\
\hline \multirow{2}{*}{ Step 3} & $\begin{array}{l}\text { Transactional } \\
\text { leadership }\end{array}$ & -0.017 & -0.464 & 0.643 & -0.006 & -0.159 & 0.874 \\
\hline & Satisfaction & 0.608 & $16.524^{* * *}$ & 0.000 & 0.559 & $14.583^{* * *}$ & 0.000 \\
\hline$F$-value & & & $137.398^{* * *}$ & & & $107.335^{* * *}$ & \\
\hline Adjusted $\mathrm{R}^{2}$ & & & 0.365 & & & 0.309 & \\
\hline
\end{tabular}

$\beta$, standardized regression coefficient; $t, t$-value; $p, p$-value; Adjusted $\mathrm{R}^{2}$, adjusted coefficient of determination; ${ }^{*} p<0.05 ;{ }^{* * *} p<0.001$.

Table 9. Mediating effects of trust on the relationship between transformational leadership and performance

\begin{tabular}{|c|c|c|c|c|c|c|c|}
\hline \multirow{2}{*}{ Step } & & \multicolumn{3}{|c|}{ Learning \& growth } & \multicolumn{3}{|c|}{ Internal process } \\
\hline & & $\beta$ & $t$ & $p$ & $\beta$ & $t$ & $p$ \\
\hline Step 1 & & 0.451 & $10.988^{* * *}$ & 0.000 & 0.451 & $10.988^{* * *}$ & 0.000 \\
\hline Step 2 & & 0.452 & $11.043^{* * *}$ & 0.000 & 0.422 & $10.147^{* * *}$ & 0.000 \\
\hline \multirow{2}{*}{ Step 3} & $\begin{array}{l}\text { Transformational } \\
\text { leadership }\end{array}$ & 0.242 & $5.975^{* * *}$ & 0.000 & 0.228 & $5.401^{* * *}$ & 0.000 \\
\hline & Trust & 0.469 & $11.561^{* * *}$ & 0.000 & 0.434 & $10.271^{* * *}$ & 0.000 \\
\hline$F$-value & & & $145.384^{* * *}$ & & & $115.908^{* * *}$ & \\
\hline Adjusted $\mathrm{R}^{2}$ & & & 0.379 & & & 0.327 & \\
\hline
\end{tabular}

$\beta$, standardized regression coefficient; $t, t$-value; $p, p$-value; Adjusted $\mathrm{R}^{2}$, adjusted coefficient of determination; ${ }^{* * *} p<0.001$.

신뢰를 가질 때 경영성과가 제고되는 동기부여가 가능하다. 즉 가맹점 직원은 고급 기술 습득의 필요성과 상위 직급으로의 승 진을 위한 교육 기회에 대한 수요가 강하여 뷰티 프랜차이즈에 서 가맹본사에 대한 만족과 신뢰는 근무성과와 상관성이 있는 것으로 보인다.

\section{4. 회귀분석 결과}

1) 변혁적 리더십과 가맹점 성과의 관계에서 만족의 매개역할

교육강사의 변혁적 리더십과 가맹점 성과의 관계에서 만족 의 매개역할을 분석한 결과는 Table 7과 같다. 분석결과 변혁 적 리더십은 1 단계에서 매개변수인 만족에 통계적으로 유의미 한 정 $(+)$ 의 영향을 미치는 것으로 나타났고 $(p<0.001), 2$ 단계 에서 종속변수인 학습과 성장 성과 및 내부 프로세스 성과에도 통계적으로 유의미한 정(+)의 영향을 미치는 것으로 나타났다 $(p<0.001)$. 또한 3 단계에서는 독립변수인 변혁적 리더십의 회 귀계수는 2 단계에 비해 적은 영향을 미치는 것으로 나타났고, 매개변수인 만족은 유의미하게 나타나 $(p<0.001)$, 만족은 변혁 적 리더십과 가맹점 성과 간 관계에서 부분매개 조건을 충족하 는 것으로 나타났다.

2) 거래적 리더십과 가맹점 성과의 관계에서 만족의 매개역할
교육강사의 거래적 리더십과 가맹점 성과의 관계에서 만족의 매개역할을 분석한 결과는 Table 8과 같다. 분석결과 거래적 리 더십은 1 단계에서 매개변수인 만족에 통계적으로 유의미한 정 $(+)$ 의 영향을 미치는 것으로 나타났고 $(p<0.05), 2$ 단계에서 종 속변수인 학습과 성장 성과 및 내부 프로세스 성과에는 통계적 으로 유의미한 정 $(+)$ 의 영향을 미치지 않는 것으로 나타났다. 또한 3 단계에서는 독립변수인 거래적 리더십의 회귀계수는 2 단 계에 비해 적은 영향을 미치는 것으로 나타났고, 매개변수인 만 족은 유의미하게 나타나 $(p<0.001)$, 만족은 거래적 리더십과 가 맹점 성과 간 관계에서 매개효과가 없는 것으로 나타났다.

3) 변혁적 리더십과 가맹점 성과의 관계에서 신뢰의 매개역할 교육강사의 변혁적 리더십과 가맹점 성과의 관계에서 신뢰 의 매개역할을 분석한 결과는 Table 9 와 같다. 분석결과 변혁 적 리더십은 1 단계에서 매개변수인 신뢰에 통계적으로 유의미 한 정 $(+)$ 의 영향을 미치는 것으로 나타났고 $(p<0.001), 2$ 단계 에서 종속변수인 학습과 성장 성과 및 내부 프로세스 성과에도 통계적으로 유의미한 정(+)의 영향을 미치는 것으로 나타났다 $(p<0.001)$. 또한 3 단계에서는 독립변수인 변혁적 리더십의 회 귀계수는 2 단계에 비해 적은 영향을 미치는 것으로 나타났고, 매개변수인 신뢰는 유의미하게 나타나 $(p<0.001)$, 신뢰는 변혁 
Table 10. Mediating effects of trust on the relationship between transactional leadership and performance

\begin{tabular}{|c|c|c|c|c|c|c|c|}
\hline \multirow{2}{*}{ Step } & & \multicolumn{3}{|c|}{ Learning \& growth } & \multicolumn{3}{|c|}{ Internal process } \\
\hline & & $\beta$ & $t$ & $p$ & $\beta$ & $t$ & $p$ \\
\hline Step 1 & & 0.068 & 1.472 & 0.142 & 0.068 & 1.472 & 0.142 \\
\hline Step 2 & & 0.048 & 1.052 & 0.293 & 0.054 & 1.178 & 0.239 \\
\hline \multirow{2}{*}{ Step 3} & $\begin{array}{l}\text { Transactional } \\
\text { leadership }\end{array}$ & 0.009 & 0.245 & 0.807 & 0.018 & 0.459 & 0.647 \\
\hline & Trust & 0.578 & $15.349^{* * *}$ & 0.000 & 0.535 & $13.756^{* * *}$ & 0.000 \\
\hline$F$-value & & \multicolumn{3}{|c|}{$118.613^{* * *}$} & \multicolumn{3}{|c|}{$95.575^{* * *}$} \\
\hline Adjusted $\mathrm{R}^{2}$ & & \multicolumn{3}{|c|}{0.332} & \multicolumn{3}{|c|}{0.285} \\
\hline
\end{tabular}

$\beta$, standardized regression coefficient; $t, t$-value; $p, p$-value; Adjusted $\mathrm{R}^{2}$, adjusted coefficient of determination; ${ }^{* * *} p<0.001$.

적 리더십과 가맹점 성과 간 관계에서 부분매개 조건을 충족하 는 것으로 나타났다.

\section{4) 거래적 리더십과 가맹점 성과의 관계에서 신뢰의 매개역할}

교육강사의 거래적 리더십과 가맹점 성과의 관계에서 신뢰 의 매개역할을 분석한 결과는 Table 10 과 같다. 분석결과 거래 적 리더십은 1단계에서 매개변수인 신뢰에 통계적으로 유의미 한 영향이 나타나지 않았고, 2 단계에서 종속변수인 학습과 성 장 성과 및 내부 프로세스 성과에도 통계적으로 유의미한 영향 을 미치지 않았다. 또한 3 단계에서는 독립변수인 거래적 리더 십의 회귀계수는 2 단계에 비해 적은 영향을 미치는 것으로 나 타났고, 매개변수인 신뢰는 유의미하게 나타나 $(p<0.001)$ 신뢰 는 거래적 리더십과 가맹점 성과 간 관계에서 매개효과가 없는 것으로 나타났다.

이와 같은 회귀분석 결과를 통해 뷰티 프랜차이즈에서 관계 품질인 만족과 신뢰는 가맹점의 학습과 성장 성과 및 내부 프 로세스 성과에 긍정적 영향을 미치므로, 가맹본사는 가맹점과 의 관계품질 제고가 중요함이 밝혀졌다. 기존의 프랜차이즈 연 구는 관계품질을 주로 가맹점주가 가맹본사와 형성하는 만족과 신뢰를 고찰하였으나(Han et al., 2011; Kwak \& Kim, 2015), 본 연구분석의 결과로써 뷰티 프랜차이즈 가맹점 직원과 가맹 본사의 관계품질이 가맹점 성과 향상에 영향을 미치는 것으로 나타났다. 이는 뷰티 프랜차이즈는 대형 브랜드 샵의 근무 경험 이 경력 관리에 긍정적 영향을 미치고 장기 근속에 따라 본사교 육 참여 기회가 보다 많이 부여되는 점이 가맹점 직원에게 중요 하기 때문으로 보인다. 또한 뷰티 프랜차이즈에서 가맹점 직원 은 서비스 제공자로서 고객과의 접점이며 가맹본사와 직접적인 커뮤니케이션 당사자이므로 프랜차이즈 관계품질은 가맹점 성 과와 밀접한 관계를 갖는 것으로 판단된다.

\section{Conclusion}

본 연구는 프랜차이즈 가맹본사 교육강사의 리더십과 가맹 점 경영성과의 관계에서 프랜차이즈 관계품질의 매개효과를 밝혀 효과적인 프랜차이즈 운영의 시사점을 제안하고자 하였 다. 연구결과 가맹본사 교육강사의 변혁적 리더십이 가맹점 경 영성과에 긍정적인 영향을 미치고, 프랜차이즈 관계품질인 만 족과 신뢰의 매개효과로 가맹점의 경영성과가 더욱 제고되는 것으로 나타났다. 그러나 가맹본사 교육강사의 거래적 리더십 은 가맹점 경영성과에 긍정적인 영향을 미치지 않고, 프랜차이 즈 관계품질의 매개효과도 나타나지 않았다.

이는 헤어 프랜차이즈에서 대형 브랜드 점포의 근무 경험이 개인 경력에 미치는 영향이 크고, 우수한 본사교육 기회가 제 공되는 점이 가맹점 직원에게 매력적인 요소이므로 가맹본사 는 가맹점 직원과의 관계품질의 중요성을 인식하고 관계품질 을 높이기 위해 프랜차이즈 매뉴얼의 체계화 및 커뮤니케이션 의 활성화가 필요하다는 것을 나타낸다.

프랜차이즈 시스템은 가맹본사, 가맹점 및 고객이 유기적인 관계를 형성한다. 가맹점 직원은 각 가맹점 소속 직원으로서 가맹본사와 직접적인 고용관계가 없더라도 가맹점의 성과 향 상은 가맹본사의 지속적인 사업수행에 필수적인 요소이다. 또 한 다른 서비스 프랜차이즈, 즉 외식 또는 유통 프랜차이즈에 비하여 뷰티 프랜차이즈에서 본사 교육 시스템은 가맹점 직원 의 동기 부여에 큰 영향을 미치며 프랜차이즈 관계품질에 따라 브랜드에 소속감과 일체감을 형성하게 된다.

따라서 뷰티 프랜차이즈 가맹본사는 교육의 제공에서 변혁 적 리더십이 적극적으로 발휘되도록 교육강사의 역량을 강화 해야 하며, 가맹점주 위주의 관계품질 형성에 그치지 않고 가 맹점 직원의 만족과 신뢰를 고취하여 가맹점의 성과를 제고함 으로써 안정적인 프랜차이즈 운영의 기반을 확고히 할 수 있을 것이다. 
This work is part of the Joon-Ho Kim's Ph.D. thesis at the Seoul Venture University, Seoul, Korea.

\section{References}

Avolio BJ, Bass BM, Jung DI. Re-examining the components of transformational and transactional leadership using the multifactor leadership. Journal of Occupational and Organizational Psychology, 72: 441-462, 1999.

Bass BM. From transactional to transformational leadership: learning to share the vision. Organizational Dynamics, 18: 19-31, 1990.

Bono JE, Judge TA. Personality and transformational and transactional leadership: a meta-analysis. Journal of Applied Psychology, 89: 901-910, 2004.

Davies MAP, Lassar W, Manolis C, Prince M, Winsor RD. A model of trust and compliance in franchise relationships. Journal of Business Venturing, 26: 321-340, 2011.

Den Hartog DN, Van Muijen JJ, Koopman PL. Transactional versus transformational leadership: an analysis of the MLQ. Journal of Occupational and Organizational Psychology, 70: 19-34, 1997.

Garbarino E, Johnson MS. The different roles of satisfaction, trust, and commitment in customer relationships. Journal of Marketing, 63: 70-87, 1999.

Geyskens I, Steenkamp JBEM. Economic and social satisfaction: measurement and relevance to marketing channel relationships. Journal of Retailing, 76: 11-32, 2000.

Han SH, Bae GC, Lee JH. The effect of franchisor's pre-open support services on franchisee's relationship quality and performance in foodservice franchise system. The Korean Journal of Franchise Management, 2: 152-172, 2011.

Hoang TTH. The relationship between franchise and franchisor: a study of the Vietnamese retail franchising. VNU Journal of Science, Economics and Business, 27: 6781, 2011.

Hwang JH, Lee SB. The effects of relational satisfaction on compliance: a focus on the mediating role of trust and dependence. Korean Journal of Hospitality and Tourism, 23: 25-44, 2014.
Hwangbo Y, Ha KS. Location factors determining hairstyle service sales. The Journal of the Korea Contents Association, 8: 296-305, 2008.

Kanste $\mathrm{O}$, Miettunen J, Kyngäs H. Psychometric properties of the multifactor leadership questionnaire among nurses. Journal of Advanced Nursing, 57: 201-212, 2007.

Kaplan RS, Norton DP. Linking the balanced scorecard to strategy. California Management Review, 39: 53-79, 1996.

Kim MJ. Effects of service factors and relationship quality on customer's behavior intention in skin-care shop. Asian Journal of Beauty and Cosmetology, 14: 389-398, 2016.

Kwak EJ, Kim DJ. The effect of coffee shop franchisor's support service on franchisee's relationship satisfaction, relationship quality, long-term orientation. International Journal of Tourism Management and Sciences, 30: 377402, 2015.

Lee MS, An JS. The study of motives to select and revitalise a franchise by comparing management practices of nail shops. Journal of Digital Convergence, 12: 201-211, 2014.

Michael SC, Combs JG. Entrepreneurial failure: the case of franchisees. Journal of Small Business Management, 46: 73-90, 2008.

Oh $\mathrm{KH}$. The impact of beauty franchise's training program on business performance: focused on the moderating effect of training satisfaction. Jounal of the Korean Society of Cosmetology, 16: 505-520, 2010.

Park SI. Analysis of factors affecting the performance of Korean franchise business by stages. Asia-Pacific Journal of Business Venturing and Entrepreneurship, 4: 89-111, 2009.

Shin JS, Cha Y. The relationship between transformational. transactional leadership and in-role performance: mediating effect of subordinator's motivation. The Journal of the Korea Contents Association, 14: 373-379, 2014.

Yang HC, Lee YC. An empirical study in relationship between franchisor's leadership behavior style and commitment by focusing moderating effect of franchisee's self-efficacy. Journal of Channel and Retailing, 15: 49-71, 2010. 


\section{국문초록}

\section{프랜차이즈 본사 리더십과 가맹점 경영성과에서 프랜차이즈 관계품질의 매개효과}

김준호 ${ }^{1}$, 윤천성 ${ }^{*}$

${ }^{1}$ 세명대학교 교양대학, 충청북도 제천시, 한국

${ }^{2}$ 서울벤처대학원대학교 융합산업학과, 서울, 한국

목적: 본 연구는 서비스 프랜차이즈 가맹본사 교육강사의 리더십과 가맹점 경영성과의 관계에서 프랜차이즈 관계품질의 매개효과 를 알아보고자 한다. 방법: 연구대상의 일반적 특성을 알아보기 위해 빈도분석을 실시하였고, 변수 선정의 타당성과 신뢰성을 검 증하기 위하여 요인분석과 Cronbach's $\alpha$ 계수를 산출하였다. 또한 변수들 간의 영향 관계를 분석하기 위해 다중회귀분석을 실시하 였다. 결과: 3 단계 매개효과 분석 결과, 교육강사의 변혁적 리더십의 회귀계수는 2 단계에 비해 적은 영향을 미치고, 매개변수인 프 랜차이즈 관계품질인 만족과 신뢰의 회귀계수는 유의하게 나타났다. 따라서 프랜차이즈 관계품질은 서비스 프랜차이즈 교육강사 의 변혁적 리더십과 가맹점의 학습과 성장 성과 및 내부 프로세스 성과 간 관계에서 부분매개 조건을 충족하는 것으로 나타났다. 결 론: 본 연구 결과, 서비스 프랜차이즈는 가맹점 직원의 교육 프로그램의 실행에서 변혁적 리더십을 더욱 적극적으로 발휘해야 하 며, 프랜차이즈 관계품질인 만족과 신뢰의 형성과 제고에 효과적인 커뮤니케이션 수단을 확립해야 한다.

핵심어: 프랜차이즈, 리더십, 만족, 신뢰, 경영성과

\section{참고문헌}

곽은정, 김동진. 프랜차이즈 커피전문점 가맹본부의 가맹점에 대한 지원이 가맹점이 지각하는 관계만족, 관계품질, 장기지향성 에 미치는 영향. 관광연구, 30: 377-402, 2015.

김민정. 피부미용실에서 서비스요인과 관계품질이 고객행동의도에 미치는 영향. 아시안뷰티화장품학술지, $14: 389-398$, 2016.

박상익. 국내 프랜차이즈 성과에 영향을 미치는 요인에 관한 연구. 벤처창업연구, 4: 89-111, 2009.

신장선, 차윤석. 변혁적 · 거래적 리더십과 직무수행성과 간의 관계. 한국콘텐츠학회논문지, 14: 373-379, 2014.

양회창, 이영철. 가맹본부의 리더십 행동유형과 가맹사업자의 관계결속에 관한 실증적 연구: 가맹사업자의 자기효능감의 조절 효과를 중심으로. 유통연구, 15: 49-71, 2010.

오경헌. 미용 프랜차이즈의 교육프로그램이 기업성과에 미치는 영향: 교육만족의 조절효과를 중심으로. 한국미용학회지, $16:$

505-520, 2010.

이미선, 안종숙. 네일샵의 경영형태 비교를 통한 프랜차이즈 선택동기와 경영성과 분석에 대한 연구. 디지털융복합연구, 12 : 201-211, 2014.

한상호, 배기철, 이재한. 외식 프랜차이즈 가맹본부 개점 전 지원서비스가 가맹점 관계품질과 경영성과에 미치는 영향. 프랜차 이즈경영연구, 2: 152-172, 2011.

황보윤, 하규수. 미용서비스업체의 입지요인과 경영성과에 관한 실증연구. 한국콘텐츠학회논문지, 8: 296-305, 2008. 황정현, 이수범. 외식프랜차이즈의 경로관계에서 관계만족과 순응의 관계에 미치는 신뢰와 의존의 매개역할. 호텔경영학연구,

23: 25-44, 2014. 


\section{中文摘要}

\section{特许经营关系质量对特许经营领导和加盟商经营绩效的中介效应}

金俊镐 ${ }^{1}$, 尹天星 ${ }^{*}$

${ }^{1}$ 世明大学教养大学, 忠清北道堤川市, 韩国

2首尔Venture大学院, 融合产业学科, 首尔, 韩国

目的: 研究特许经营关系质量对特许经营加盟总店教育讲师的领导能力与加盟商经营绩效关系的中介作用。方法: 利用频 度分析调查研究对象的一般特性, 为验证变量选择的有效性和可靠性, 计算因子分析和Cronbach's $\alpha$ 系数。此外, 为分 析变量之间的影响关系, 进行多元回归分析。结果: 在三步介导的回归中, 教育讲师的变革型领导的回归系数在第三阶 段比第二阶段小，此外，特许经营的关系质量即满意度和信任度的回归系数显著出现。因此，特许经营关系质量对特许 经营教育讲师的变革型领导与加盟店的学习, 成长绩效以及内部过程绩效之间的关系中部分充当中介条件。结论: 在加 盟商员工培训计划的实施中, 需积极发挥变革领导能力, 建立有效的沟通方式, 形成和提高特许经营关系质量的满意度 和信任度。

关键词: 特许经营, 领导能力, 满足, 信任, 经营绩效 